\title{
ANALISIS TINGKAT KEHIJAUAN HUTAN DAERAH PERTAMBANGAN SAWAHLUNTO DENGAN METODE NDVI BERDASARKAN CITRA LANDSAT TAHUN 2006-2016
}

\author{
Bowo Eko Cahyono $^{\text {a) }}$, Yazella Feni Frahma ${ }^{\text {b) }}$, Agung Tjahjo Nugroho ${ }^{\text {c) }}$ \\ Jurusan Fisika, Fakultas MIPA, Universitas Jember Jalan Kalimantan 37, Jember 68121 \\ Email: ${ }^{a}$ bowo_ec.fmipa@unej.ac.id, b)yazella.31@gmail.com, ${ }^{\text {c) }}$ agungtj.fmipa@unej.ac.id
}

\begin{abstract}
Abstrak
Pembukaan lahan hutan yang dijadikan lokasi pertambangan merupakan salah satu kegiatan yang dapat merubah jenis tutupan lahan atau sering disebut dengan konversi lahan. Salah satu daerah yang telah mengalami konversi lahan tersebut adalah Sawahlunto. Konversi lahan yang tidak menggunakan prinsip kelestarian lingkungan dapat mengakibatkan banyak hal negatif misalnya degradasi atau penurunan kualitas hutan. Tujuan dari penelitian ini adalah melakukan analisis tingkat degradasi hutan daerah pertambangan Sawahlunto tahun 2006 sampai 2016. Penelitian ini menggunakan teknologi penginderaan jauh berbasis citra satelit landsat. Citra satelit landsat ini diklasifikasikan dengan metode Normalized Difference Vegetation Index (NDVI) berdasarkan kerapatan vegetasi. Kemudian hasil klasifikasi ini dibuat dalam bentuk pemetaan. Klasifikasi pertama dikategorikan menjadi dua yakni hutan dan non hutan. Hasil yang didapatkan dari penelitian ini menunjukkan bahwa terjadi perubahan tutupan lahan yang semula hutan menjadi non hutan meningkat sebesar 7,5\% selama kurun waktu sepuluh tahun. Klasifikasi selanjutnya yakni berdasarkan enam kategori yakni vegetasi sangat rapat, rapat, cukup rapat, non vegetasi 1, 2 dan 3. Dari klasifikasi ini, juga terlihat perubahan nilai NDVI maksimum maupun minimumnya. Tahun 2006 memiliki kisaran nilai NDVI maksimum 0,71 dan tahun 2016 memiliki kisaran nilai NDVI maksimum 0,56. Hal ini mengidentifikasi bahwa tingkat kehijauan yang ada di daerah pertambangan Sawahlunto menurun.
\end{abstract}

Kata Kunci : degradasi, hutan, landsat, ndvi, klasifikasi, Sawahlunto.

\begin{abstract}
The clearing of forest land that is used as a mining site is one of the activities that can change the type of land cover or often called land conversion. One of the forest areas that convert the land is Sawahlunto. Conversion of land that does not use the principles of environmental sustainability can lead to many negative things one of which is the degradation. The purpose of this research is to analyze the level of forest degradation of Sawahlunto mining area in 2006 until 2016. This research uses a remote sen sing technology based on landsat satellite imagery. This landsat satellite image is classified by Normalized Difference Vegetation Index (NDVI) method based on vegetation density. Then the results of this classification is made in the form of mapping. The first classification is categorized into two namely forest and non forest. The results obtained from this study indicate that a change in land cover from forest to non-forest increased by $7.5 \%$ over a period of ten years. The next classification is based on six categories namely very dense vegetation, dense vegetation, fairly dense, non vegetation 1, 2 and 3. From this classification, also seen the change in NDVI maximum and minimum value. The year 2006 has a maximum NDVI value range of 0.71 and 2016 has a maximum NDVI value range of 0.56 . This identifies that the existing greenness in the mining area of Sawahlunto is decreasing.
\end{abstract}

Keyword : degradation, forest, landsat, ndvi, classification, Sawahlunto.

\section{PENDAHULUAN}

Sawahlunto merupakan daerah yang terkenal dengan pertambangan batu bara [1]. Aktifitas pertambangan batu bara sudah dilakukan sejak lama. Puluhan juta ton batu bara telah dihasilkan dari 
daerah tersebut. Tahun 2010 terdapat setidaknya sepuluh perusahaan tambang yang telah beroperasi. Apabila semakin lama kegiatan pertambangan tersebut berjalan maka akan semakin merusak ekosistem hutan dan secara otomatis akan mengubah jenis tutupan lahan yang ada di sana. Sawahlunto memiliki luas $273,45 \mathrm{~km}^{2}$ dan lebih dari 27 persennya adalah kawasan perbukitan yang ditutupi oleh hutan lindung yang masuk dalam daerah Bukit Barisan [2]. Kurangnya informasi mengenai adanya degradasi dan perubahan alih fungsi hutan dari tahun 2006 sampai 2016 menjadi salah satu faktor diperlukannya penelitian ini. Salah satu cara yang digunakan untuk pemantauan degradasi hutan adalah dengan memanfaatkan citra satelit yang biasa disebut dengan teknologi penginderaan jauh atau remote sensing $[3,4,5]$.

Teknologi penginderaan jauh merupakan teknologi yang dapat digunakan untuk memperoleh informasi tentang obyek di permukaan bumi dengan cara menganalisis data yang diperoleh dengan menggunakan alat tanpa kontak langsung terhadap obyek yang dikaji [6]. Perolehan data mengenai obyek tersebut dapat menggunakan sebuah alat jarak jauh misalnya satelit, pesawat angkasa, dan sebagainya [7]. Penggunaan citra satelit untuk mendeteksi penggunaan lahan (Land Use) cukup banyak digunakan karena memiliki cakupan wilayah yang luas dan waktu yang dibutuhkan singkat. Data citra satelit memiliki resolusi spasial, temporal maupun spektral yang berbeda-beda sehingga dalam aplikasinya penggunaan data tersebut disesuaikan dengan kebutuhan informasi yang ingin didapatkan. Pemanfaatan teknologi penginderaan jauh untuk pemantauan tutupan lahan telah berkembang dengan baik tetapi tetap terjadi kecenderungan akan peningkatan kebutuhan informasi yang lebih detail $[8,9,10]$.

Penelitian sebelumnya terkait penggunaan teknologi penginderaan jauh untuk analisis tutupan lahan telah dilakukan oleh Catur, et al [11]. Mereka melakukan identifikasi lahan tambang timah menggunakan metode klasifikasi supervised dengan memanfaatkan data citra Land Satelite (LANDSAT). Dari penelitian yang mereka lakukan tersebut, diperoleh ciri-ciri lahan tambang timah pada citra landsat 8 yakni mempunyai warna coklat terang sampai putih cerah, tekstur kasar, mengikuti pola sungai, memliki ukuran lahan yang luas dan terdapat kubangan air yang berwarna biru. Tingkat akurasi yang dihasilkan dari penelitian tersebut adalah 90,5 persen.

Analisis tutupan lahan dengan menggunakan penginderaan jauh juga banyak diaplikasikan untuk mendeteksi degradasi hutan [3, 12]. Metode yang digunakan yaitu klasifikasi vegetasi sehingga bisa membedakan antara hutan dan non hutan [13, [14]. Penelitian lain tentang klasifikasi vegetasi yakni pada tahun 2008 yang dilakukan oleh Sudiana dan Diasmara [15]. Dalam penelitiannya mereka melakukan analisis keadaan vegetasi yang ada di Pulau Kalimantan dengan menggunakan metode Enhanced Vegetation Index (EVI). Hasil dari penelitian tersebut yakni dapat memetakan daerah atau wilayah yang mempunyai tingkat kehijauan tinggi dan daerah yang tingkat kehijauannya rendah. Dari penelitian tersebut juga dapat diketahui perbedaan tingkat kehijauan dari tahun ke tahun.

Berdasarkan permasalahan dan penelitian sebelumnya tersebut, penulis tertarik untuk melakukan analisis degradasi hutan daerah pertambangan Sawahlunto dengan menggunakan citra landsat dengan bantuan pengolahan teknologi penginderaan jauh. Tujuan dari penelitian ini adalah memantau serta menganalisis degradasi maupun tingkat kehijauan vegetasi daerah Sawahlunto dari tahun 2006 sampai 2016.

\section{METODE PENELITIAN}

Data yang digunakan pada penelitian ini adalah data citra dari satelit landsat 5 dan 8 Sawahlunto dengan path 127 dan row 060 pada tahun 2006 dan 2016. Skala peta yang digunakan adalah 1:60.000. Pada penelitian ini, tidak semua wilayah Sawahlunto dijadikan obyek penelitian. Hanya daerah di sekitar area pertambangan yang dijadikan daerah penelitian. Hal ini dilakukan agar hasil penelitian bisa tepat sasaran yakni pemantauan daerah sekitar area pertambangan Sawahlunto. Daerah

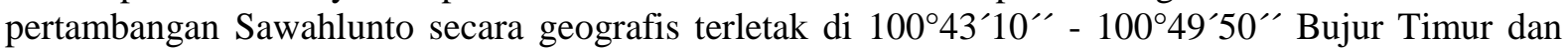
$0^{\circ} 34^{\prime} 30^{\prime \prime}-0^{\circ} 39^{\prime} 00^{\prime \prime}$ Lintang Selatan. Peta lokasi penelitian ditunjukkan pada Gambar 1 berikut ini. 


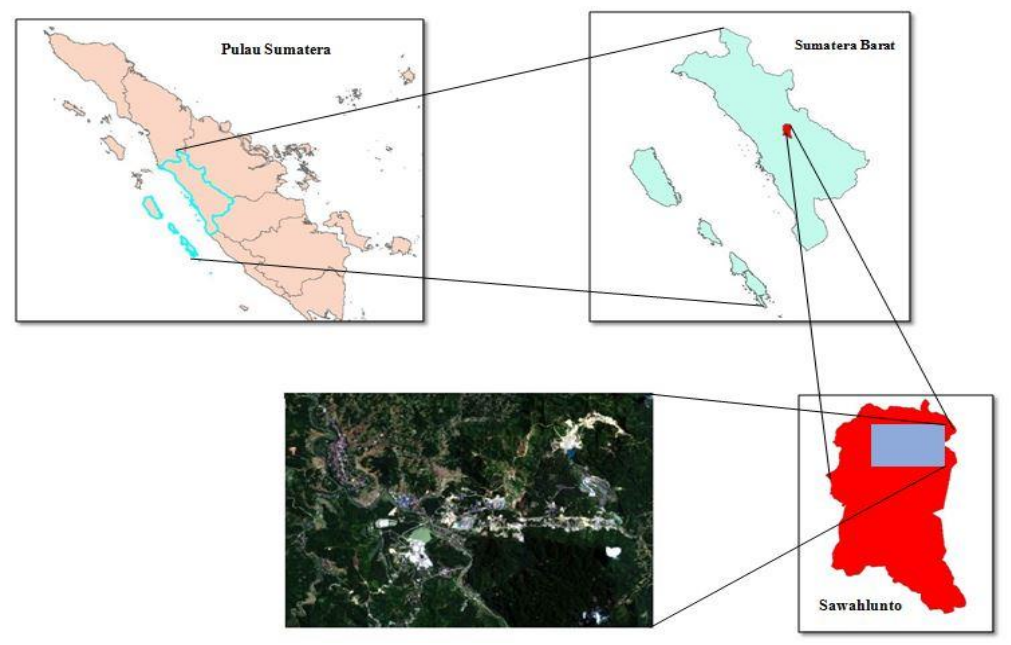

Gambar 1 Daerah penelitian

Sedangkan tahapan penelitian yang dilakukan digambarkan dalam bentuk diagram alir seperti diberikan pada Gambar 2.

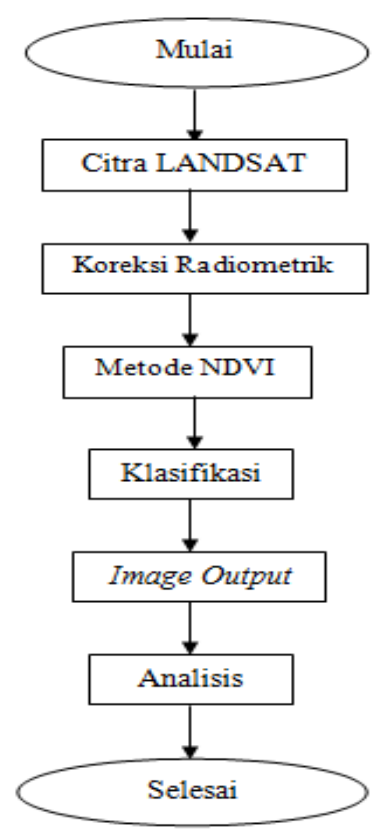

Gambar 2 Diagram alir penelitian

\section{Koreksi Radiometrik}

Hal pertama yang dilakukan adalah koreksi radiometrik dan pemotongan citra sesuai dengan daerah penelitian. Menurut Menurut Catur, et al ${ }^{[11]}$ rumusan untuk koreksi radiometrik adalah sebagai berikut:

$$
L \lambda=M L \times Q c a l+A L
$$

di mana;

$L \lambda=$ ToA reflektansi

$M L=$ Reflectance_Mult_Band_x

$A L=$ Reflectance_Add_Band_x

$Q c a l=$ Nilai digital number $(\mathrm{DN})$ 


\section{Normalize Difference Vegetation Index (NDVI)}

Untuk mengetahui tingkat kehijauan vegetasi yang ada di daerah pertambangan Kota Sawahlunto maka dilakukanlah analisis menggunakan metode indek vegetasi. Pada penelitian ini digunakan metode indeks vegetasi yakni Normalize Difference Vegetation Index (NDVI). Nilai NDVI didapat dari band red dan band near infrared. Karena kedua panjang gelombang ini mempunyai karakteristik yang bisa membedakan antara obyek vegetasi dan non vegetasi. Algoritma yang digunakan adalah sebagai berikut:

$$
N D V I=\frac{N I R-R E D}{N I R+R E D}
$$

Berikut ini merupakan pola spektral dari obyek vegetasi berdasarkan panjang gelombang biru, hijau, merah dan infra merah dekat.

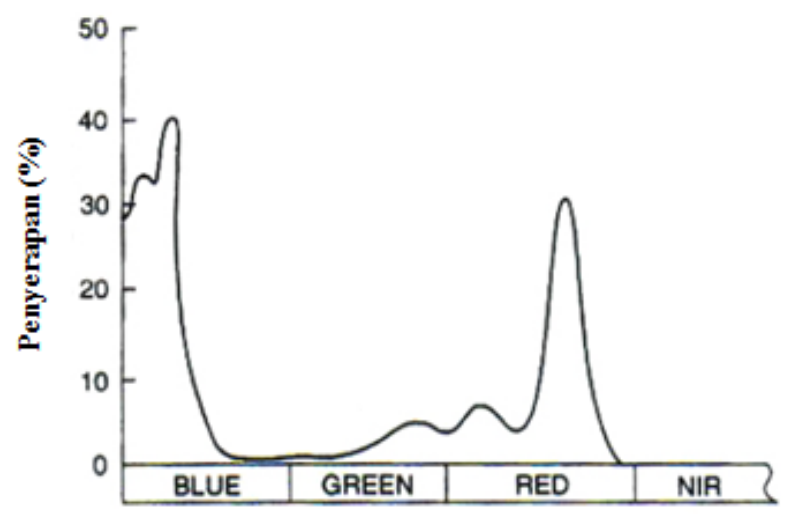

Gambar 3 Pola spektral vegetasi (Sumber: Sutanto ${ }^{[16]}$ )

Normalized Difference Vegetation Index (NVDI) adalah perhitungan citra yang digunakan untuk mengetahui tingkat kehijauan. Nilai NDVI adalah suatu nilai untuk mengetahui tingkat kehijauan pada daun dengan panjang gelombang inframerah yang sangat baik sebagai awal dari pembagian daerah vegetasi. Karena sifat optik klorofil sangat khas yaitu klorofil menyerap spektrum merah dan memantulkan dengan kuat spektrum infra merah.

Menurut Curran ${ }^{[17]}$, nilai NDVI dapat menunjukkan parameter yang berhubungan dengan parameter vegetasi, antara lain, biomass dedaunan hijau, daerah dedaunan hijau yang merupakan nilai yang dapat diperkirakan untuk pembagian vegetasi. NDVI pada dasarnya menghitung seberapa besar penyerapan radiasi matahari oleh tanaman terutama bagian daun. Nilai NDVI merupakan perbedaan reflektansi dari kanal inframerah dekat dan kanal cahaya tampak (merah).

\section{HASIL PENELITIAN}

Pada bagian ini akan diuraikan pembahasan mengenai tingkat kehijauan hutan daerah pertambangan Sawahlunto berdasarkan metode NDVI. Sebelum suatu citra dilakukan pengolahan maka citra landsat tersebut dilakukan koreksi terlebih dahulu. Pada penelitian ini, metode koreksi yang digunakan adalah koreksi radiometrik. Koreksi citra ini dilakukan agar perbedaan nilai spektral yang terjadi akibat sensor dan perbedaan waktu perekaman dapat dikurangi serta untuk meningkatkan kontras tiap pixel. Perbedaan gambar dari citra Landsat sebelum dan setelah dikoreksi geometrik tampak pada Gambar 4 dan Gambar 5. 


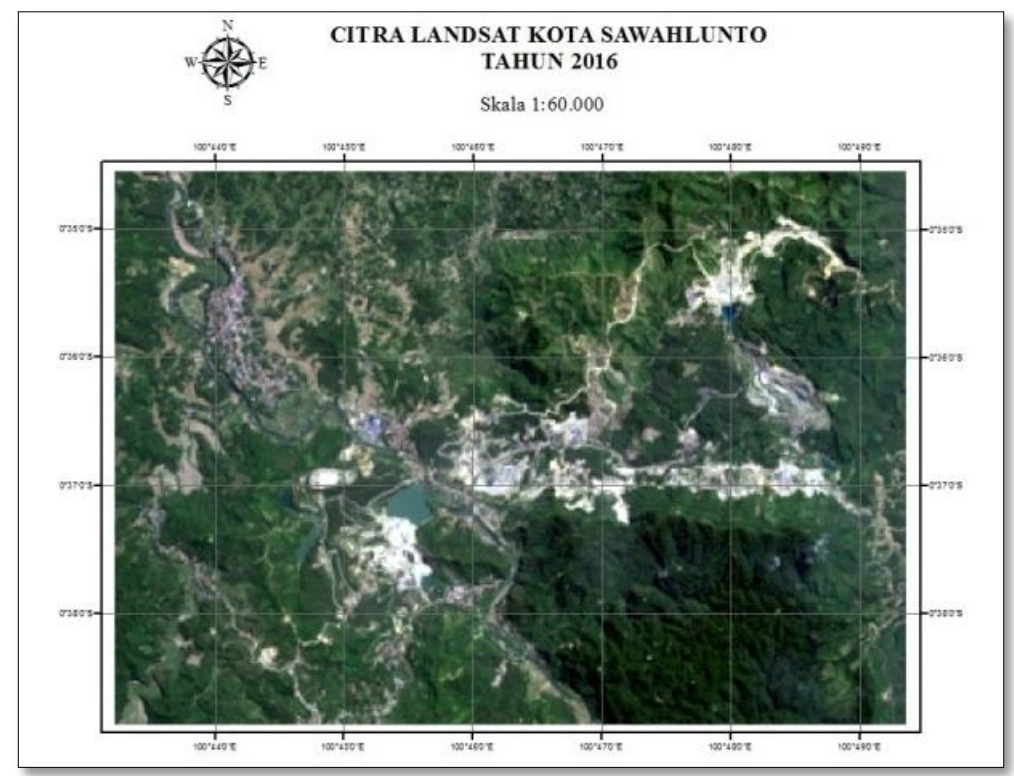

Gambar 4 Citra satelit landsat tahun 2016 sebelum dikoreksi radiometrik

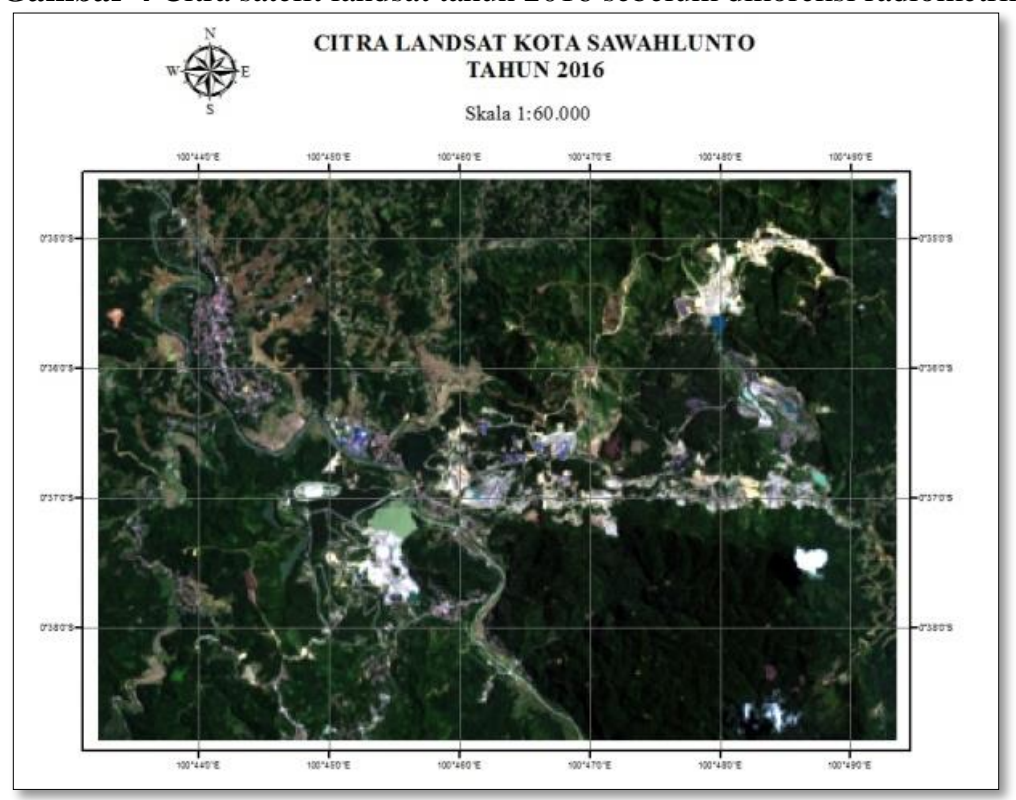

Gambar 5 Citra satelit landsat tahun 2016 sesudah dikoreksi radiometrik

Dari kedua gambar tersebut, citra landsat yang sudah dilakukan koreksi radiometrik (Gambar 5) mempunyai kontras yang lebih cerah jika dibandingkan dengan citra landsat yang belum dikoreksi radiometrik (Gambar 4). Perbedaan kontras inilah yang akan membuat proses klasifikasi selanjutnya lebih mudah, karena dapat membedakan antara obyek satu dengan yang lainnya.

Pada penelitian ini juga digunakan data citra landsat yang besarnya cloud cover $<15 \%$, agar nantinya diperoleh data yang akurat. Apabila cloud cover lebih dari $15 \%$ kemungkinan ada awan yang menghalangi gelombang elektromagnetik yang memancarkan ke obyek di permukaan bumi sehingga bisa dipantulkan kembali ataupun diserap oleh awan tersebut. Dan hanya sebagian gelombang elektromangnetik yang sampai ke obyek dipermukaan bumi. Apabila hal ini terjadi, maka akan mempengaruhi data yang dihasilkan. Karena teknologi penginderaan jauh berbasis data citra satelit landsat menggunakan sensor pasif.

Setelah data citra landsat tersebut dilakukan koreksi radiometrik maka dilanjutkan dengan metode Normalized Difference Vegetation Index (NDVI). Metode NDVI ini akan menghasilkan data tingkat kehijauan suatu daerah, sehingga bisa dibandingkan antara dua nilai NDVI yang berbeda tahun. Pada metode NDVI ini diperlukan band red dan band infrared, karena panjang gelombang 
yang berada pada band tersebut sangat peka terhadap vegetasi atau tumbuhan. Sehingga sangat tepat jika ingin melihat tingkat degradasi dan tinngkat kehijauan suatu daerah.

Pengklasifikasian pertama dilakukan berdasarkan dua jenis tutupan lahan yakni hutan dan non hutan. Berikut merupakan hasil ektraksi dengan menggunakan metode NDVI pada citra landsat tahun 2006 dan tahun 2016. Warna hijau menunjukkan area hutan dan warna hitam menunjukkan area non hutan.

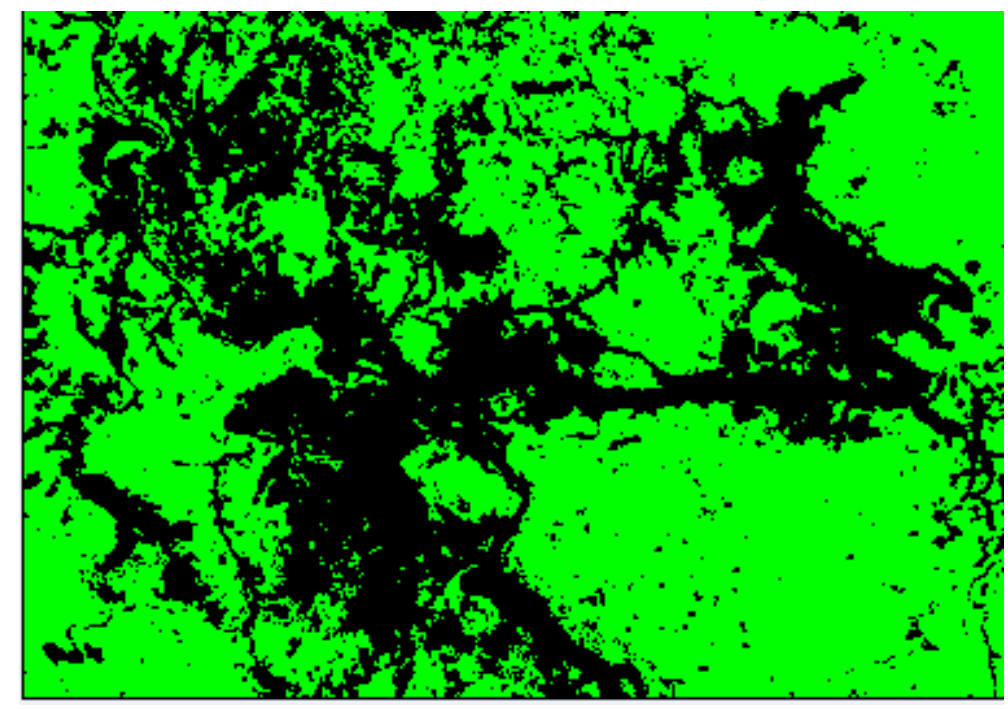

Gambar 6 Hasil citra NDVI hutan dan non hutan tahun 2006

Untuk membedakan antara citra NVI hutan dan non hutan tahun 2006 dan 2016 maka dilakukan pengamatan di daerah atau wilayah yang mengalami perubahan tutupan lahan. Hasil menunjukkan bahwa, terlihat ada perubahan tutupan lahan selama kurun waktu sepuluh tahun yang ditandai dengan lingkaran merah pada Gambar 7. Lingkaran merah pada Gambar 7 menunjukkan bahwa daerah tersebut ditahun 2006 masih hijau, yang artinya bahwa masih hutan dan ditahun 2016 sudah berubah tutupan lahannya menjadi non hutan.

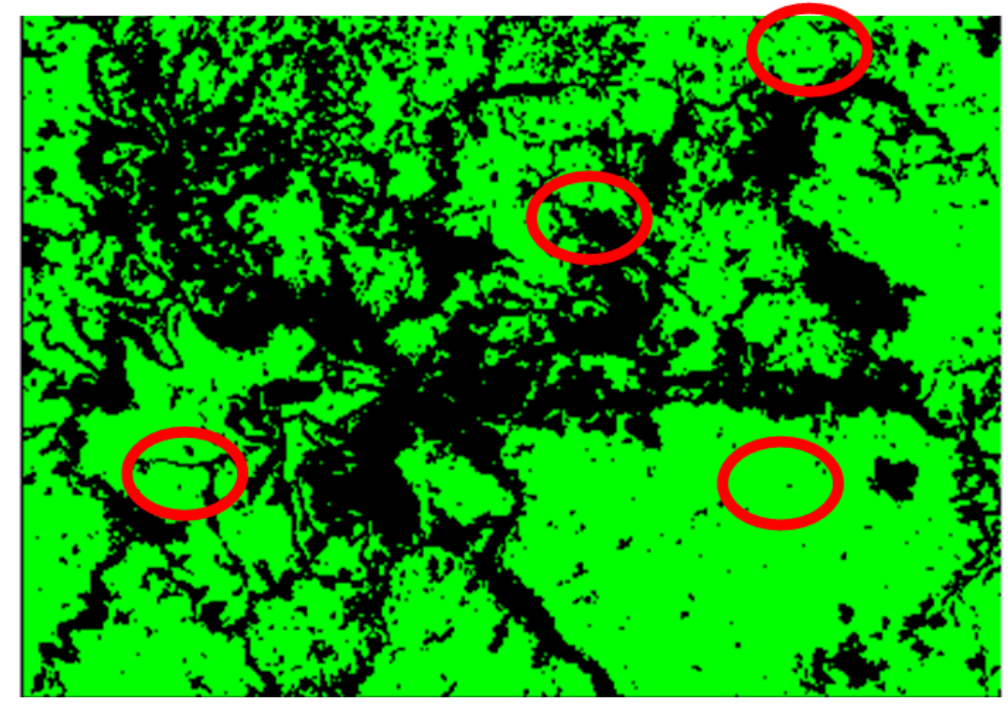

Gambar 7 Hasil citra NDVI hutan dan non hutan tahun 2016

Untuk mengetahui seberapa luas perubahan hutan menjadi non hutan selama kurun waktu sepuluh tahun maka dilakukanlah perhitungan statistik berdasarkan pengklasifikasian dua jenis tutupan lahan tersebut. Luas hutan tahun 2006 adalah $55.225 .800 \mathrm{~m}^{2}$, tahun 2016 adalah 48.359 .700 $\mathrm{m}^{2}$. Sedangkan luas non hutan di tahun 2006 adalah $35.746 .200 \mathrm{~m}^{2}$ dan tahun 2016 bertambah menjadi $42.612 .300 \mathrm{~m}^{2}$. Terjadi penurunan luas hutan yang semula $60,7 \%$ dari luas total daerah penelitian menjadi $53,2 \%$. 
Luas hutan yang ada di daerah pertambangan Sawahlunto berkurang sebesar 7,5\% selama kurun waktu sepuluh tahun, dari tahun 2006 sampai 2016. Hasil ini senada dengan hasil penelitian yang dilakukan oleh Margono et al. [3] dimana untuk kawasan Sumatra ada pengurangan sebesar 7,54 Mha selama dua dekade yakni dari 1990 sampai 2010. Berkurangnya luas hutan di Sawahlunto ini terkonfirmasi berdasarkan data luas wilayah non hutan bertambah dari yang semula hanya $39,2 \%$ dari luas daerah penelitian menjadi 46,8\%. Penggunaan lahan non hutan di daerah Sawahlunto didominasi oleh area pertambangan, pemukiman, sungai, danau bekas tambang dan lahan kosong.

Dikarenakan pada proses pengklasifikasian menjadi dua macam belum menunjukkan tingkat kehijauan vegetasi nya maka dilakukanlah pengklasifikasian menjadi enam jenis. Pemilihan enam jenis pengklasifikasian ini dikarenakan agar memudahkan dalam menganalisa tingkat kehijauan di setiap obyek tutupan lahan. Pengklasifikasian selanjutnya berdasarkan enam jenis tutupan lahan.

1. Vegetasi sangat rapat ditandai dengan warna biru tua. Area ini didominasi oleh hutan yang berada di daerah pegunungan yang sangat lebat dan hutan semak belukar.

2. Vegetasi rapat ditandai dengan warna biru muda. Area ini hampir merata di seluruh daerah penelitian didominasi oleh hutan yang sedikit tidak lebat.

3. Vegetasi cukup rapat ditandai dengan warna hijau. Area ini didominasi disekitar sungai dan pemukiman.

4. Non vegetasi tingkat 1 ditandai dengan warna kuning. Area ini didominasi oleh daerah pemukiman masyarakat, sungai dan lahan gersang.

5. Non vegetasi tingkat 2 ditandai dengan warna orange. Area ini didominasi oleh daerah pertambangan yang sudah lama diekploitasi.

6. Non vegetasi tingkat 3 ditandai dengan warna coklat. Area ini didominasi oleh daerah pertambangan yang baru saja diekploitasi.

Peta 6 jenis klasifikasi tingkat kehijauan pada daerah penelitian ditunjukkan pada Gambar 8 dan Gambar 9.

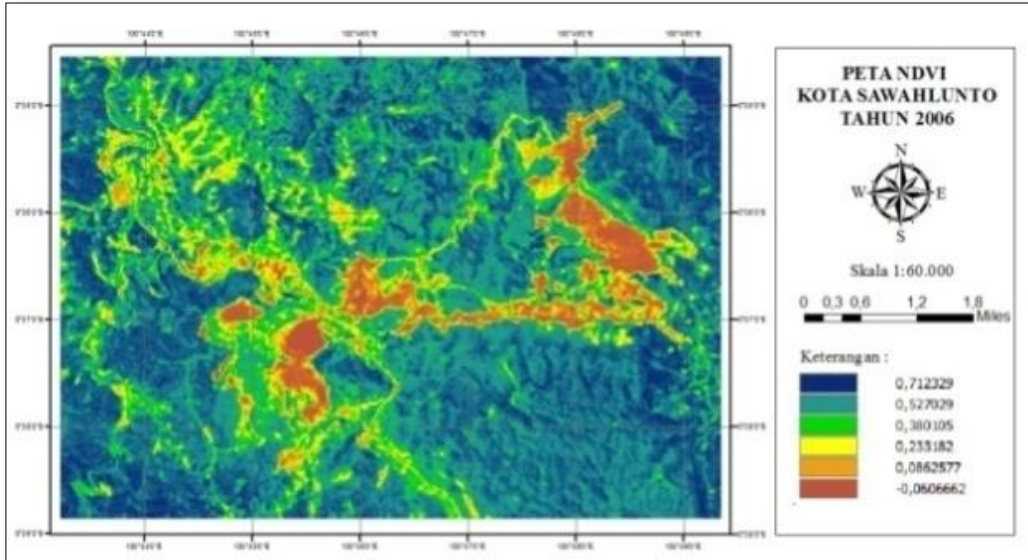

Gambar 8 Hasil citra NDVI tahun 2006 


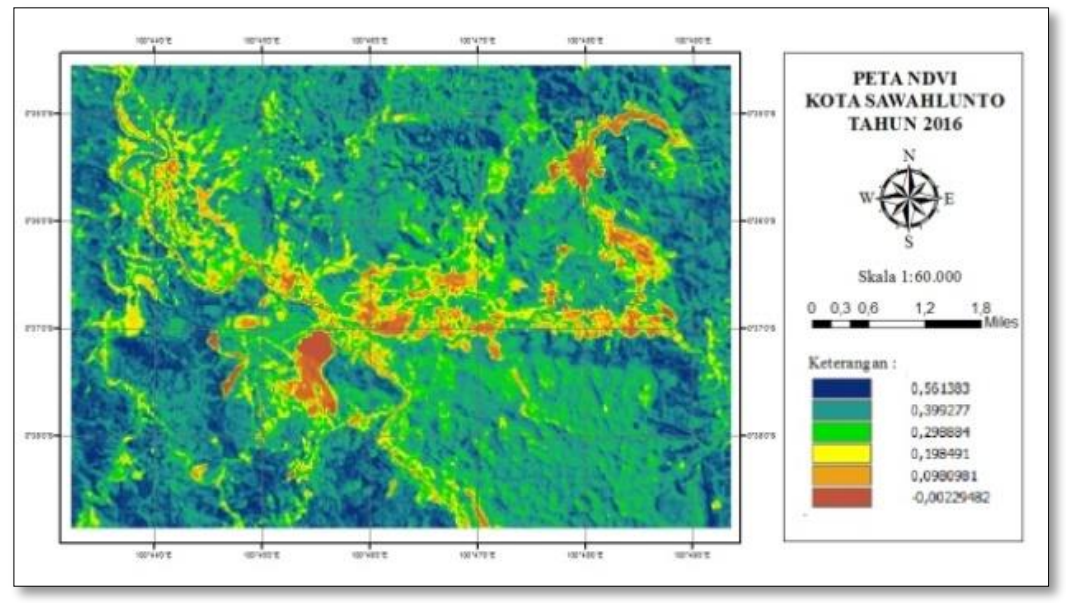

Gambar 9 Hasil citra NDVI tahun 2016

Berdasarkan hasil analisis nilai NDVI maksimum dan minimum dari dua citra landsat yang berbeda tahun tersebut menandakan bahwa tingkat kehijauan yang ada di daerah pertambangan Sawahlunto juga berubah. Nilai maksimum NDVI tahun 2006 lebih tinggi daripada nilai NDVI tahun 2016. Pada tahun 2006 nilai NDVI maksimum adalah 0,71. Nilai 0,71 masuk kategori vegetasi sangat lebat ditandai dengan warna biru. Warna biru mengidentifikasi bahwa daerah tersebut masih ditanami tumbuhan yang sangat subur dan lebat. Hal ini terlihat bahwa untuk klasifikasi kategori vegetasi sangat rapat tingkat kehijauannya menurun. Begitu pula dengan kategori lainnya yang semakin menunjukkan penurunan nilai NDVI dari tahun 2006-2016.

\section{SIMPULAN}

Perubahan tutupan lahan yang terjadi di Sawahlunto dari tahun 2006 sampai 2016 ditandai dengan perbedaan hasil perhitungan luas setiap klasifikasi. Tahun 2006 luas hutan masih 55.225.800 $\mathrm{m}^{2}$ sedangkan pada tahun 2016 sudah berkurang menjadi $48.359 .700 \mathrm{~m}^{2}$. Terjadi penurunan luas hutan sebesar 7,5\% selama kurun waktu sepuluh tahun. Begitu juga dengan tingkat kehijauan vegetasi dari tahun 2006 sampai 2016 mengalami perubahan. Tahun 2006 menghasilkan nilai maksimum NDVI sebesar 0.71 dan tahun 2016 sebesar 0.56. Hasil yang diperoleh menunjukkan bahwa nilai maksimum NDVI dari tahun 2006 sampai 2016 semakin kecil. Penurunan nilai NDVI ini dapat mengidentifikasi bahwa tingkat kehijauan yang ada di Sawahlunto menurun hal ini berkaitan dengan masalah degradasi hutan yang terjadi dari tahun 2006 sampai 2016.

\section{UCAPAN TERIMA KASIH}

Penulis mengucapkan terima kasih kepada tim remote sensing Jurusan Fisika yang telah membantu dalam penelitian ini.

\section{REFERENSI}

[1] G. B. Suprayoga, "Identitas Kota Sawahlunto Paska Kejayaan Pertambangan Batu Bara," Jurnal Perencanaan Wilayah dan Kota, vol. 19 (2), pp. 1-21, 2 Agustus 2008, 2008.

[2] "Badan Pusat Statistik," Statistik Daerah Sawahlunto 2015, Badan Pusat Statistik Sawahlunto, 2015.

[3] B. A. Margono, S. Turubanova, I. Zhuravleva et al., "Mapping and monitoring deforestation and forest degradation in Sumatra (Indonesia) using Landsat time series data sets from 1990 to 2010," Environmental Research Letters, vol. 7, pp. 1-16, 2012. 
[4] E. A. T. Matricardi, D. L. Skole, M. A. Pedlowski et al., "Assessment of tropical forest degradation by selective logging and fire using Landsat imagery," Remote Sensing of Environment, vol. 114 (5), pp. 1117-1129, 2010.

[5] D. Plugge, T. Baldauf, and M. Köhl, Reduced Emissions from Deforestation and Forest Degradation (REDD): Why a Robust and Transparent Monitoring, Reporting and Verification $(M R V)$ System is Mandatory, Institute for World Forestry University of Hamburg, Hamburg, 2011.

[6] F. F. Sabins, Remote Sensing: Principles and Interpretation, $2^{\text {nd }}$ ed., New York: W.H. Freeman and Company, 1987.

[7] T. M. Lillesand, and R. W. Keifer, Remote Sensing and Image Interpretation, $4^{\text {th }}$ ed., New York: John Wiley \& Sons, Inc, 2004.

[8] F. S. Al-Ahmadi, and A. S. Hames, "Comparison of Four Classification Methods to Extract Land Use and Land Cover from Raw Satellite Images for Some Remote Arid Areas, Kingdom of Saudi Arabia," JKAU; Earth Sci, vol. 20 (1), pp. 167-191, 2009.

[9] J. Compton, Tucker, J. R. G. et al., "African Land-Cover Classification Using Satellite Data," Science, vol. 227 (4685), 1985.

[10] H. Eva, and E. F. Lambin, "Fires and Land-Cover Change in the Tropics: A Remote Sensing Analysis at the Landscape Scale," Journal of Biogeography, vol. 27 (3), pp. 765-776, 2000.

[11] U. Catur, Susanto, D. Yudhatama et al., Identifikasi Lahan Tambang Timah Menggunakan Metode Klasifikasi Terbimbing Maximum Likelihood Pada Citra Landsat 8, Pusat Pemanfaatan Penginderaan Jauh (LAPAN), Jakarta, 2015.

[12] A. J. Langner, "Monitoring Tropical Forest Degradation and Deforestation in Borneo, Southeast Asia," 2009.

[13] K. Jia, S. Liang, X. Wei et al., "Land Cover Classification of Landsat Data with Phenological Features Extracted from Time Series MODIS NDVI Data," Remote Sensing, vol. 6 (11), pp. 11518-11532, 2014.

[14] S. W. Running, T. R. Loveland, L. L. Pierce et al., "A Remote Sensing Based Vegetation Classification Logic for Global Land Cover Analysis," Remote Sensing of Environment, vol. 51, pp. 39-48, 1995.

[15] D. Sudiana, and E. Diasmara, "Analisa Indeks Vegetasi Menggunakan Data Satelit NOAA/AVHRR dan TERRA/AQUA-MODIS." pp. 423-428.

[16] Sutanto, Penginderaan Jauh Jilid 1, Yogyakarta: Gajah Mada University Press, 1994.

[17] P. J. Curran, Principles of Remote Sensing, UK: Longman Scientific \& Technical, 1985. 
Volume 3 Nomor 1, April 2018
p-ISSN: 2541-3384 e-ISSN: 2541-3392 